\title{
The optimal analysis of skills and strengths in college basketball training
}

\author{
Sihong $\mathrm{Mi}^{1, \text { a }}$ \\ ${ }^{1}$ Department of Basic, Jiangxi Vocational College of Industry and Engineering, Pingxiang Jiangxi \\ 337055, China; \\ aallwl2005@163.com
}

Keywords: sport-specific conditioning, games-based training, basketball practice, basketball drills, basketball training

\begin{abstract}
Differences in physiological, physical, and technical demands of the college basketball training related to the number of players, court size, and work-to-rest ratios are not well characterized. A controlled trial was conducted to compare the influence of number of players $(2 \mathrm{v} 2 / 4 \mathrm{v} 4)$, court size (half/full court) and work-to-rest ratios $(4 \times 2.5 \mathrm{~min} / 2 \times 5 \mathrm{~min})$ on the demands of college games. Sixteen elite male and female undergraduate students (aged 18-22 years) completed eight variations of a college basketball training in randomized order over a six-week period. Heart rate responses and rating of perceived exertion (RPE) were measured to assess the physiological load. Movement patterns and technical elements were assessed by video analysis. There were $60 \%$ more technical elements in $2 \mathrm{v} 2$ and $~ 20 \%$ more in half court games. Heart rate $(86+4 \% \& 83+5 \%$ of maximum; mean $+\mathrm{SD})$ and RPE $(8+2 \& 6+2$; scale $1-10)$ were moderately higher in $2 \mathrm{v} 2$ than $4 \mathrm{v} 4$ small-sided games, respectively. The $2 \mathrm{v} 2$ format elicited substantially more sprints $(36+12 \%$; mean $+90 \%$ confidence limits) and high intensity shuffling $(75+17 \%)$ than $4 v 4$. Full court games required substantially more jogging $(9+6 \%)$ compared to half court games. Fewer undergraduate students in college basketball training substantially increases the technical, physiological and physical demands.
\end{abstract}

\section{Introduction}

Over the last decade, a new approach to improving college team-sport fitness has been developed in the form of game-based conditioning[1]. The purported benefits of game-based conditioning include greater transfer of physiological adaptations when the exercise simulates sports-specific movement patterns, athletes simultaneously develop technical and tactical skills under high physical loads, and higher motivation of athletes performing sport-specific rather than traditional conditioning. Sport specific conditioning in the form of college team-sport games has been evaluated extensively such as football, volleyball, but less so in basketball. The small number of research studies on basketball training is surprising given the almost universal use of college basketball training in both junior and senior programs[2-3].

Sport-specific conditioning can provide a similar or perhaps greater increase in physical fitness than traditional conditioning drills. Game-based conditioning can elicit improvements in performance in competition through improvements in skill execution[4]. Given the likely benefits of college basketball training in practice in improving both skills and conditioning, it is important to characterize (under controlled conditions) variables of training prescription that influence the relative contributions of the physical (movement patterns), physiological (cardiovascular), and technical (skill repetition) demands of various college basketball training[5]. The organizational pattern of college basketball training defines the balance between physical and physiological demands and technical practice needed for competitive success.

The aim of this study was to quantify the magnitudes of difference in physical, physiological and technical demands in various types of college basketball training to assess the influence of number of players ( $2 \mathrm{v} 2$ versus $4 \mathrm{v} 4)$, court size (half versus full) and work-to-rest ratio (4x2.5 min vs. $2 \times 5 \mathrm{~min})$. The existing research on college games, particularly in football, is informative but basketball specific research is needed to clarify important questions for college basketball training program and Physical education teachers. 


\section{Methods}

\section{Experimental approach}

A controlled experimental trial was conducted to assess the physiological, physical and technical demands of college basketball training. The combination of player number (two players per team 7 $2 \mathrm{v} 2$, or four players per team $74 \mathrm{v} 4)$, court size (half or full court) and work-to-rest ratio $(4 \times 2.5 \mathrm{~min}$ or $2 \times 5 \mathrm{~min}$ ) resulted in eight variations of small-sided games. Small-sided games using the half-court size were created by incorporating a second basketball hoop, 3-point line and keyway at the halfway line. Creating a half-court game in this manner was necessary to ensure the entire half-court area (15 $614 \mathrm{~m}$ ) was used and rules were consistent between half-court and full-court games. The 4x2.5 min games were divided into four 2.5 min quarters with a one minute rest interval between each quarter. The $2 \times 5$ min small-sided games involved two five minute halves with a 30 second rest at half time which allowed teams to switch sides. The experimental design involved the participants playing each college basketball training in a randomized order. The small-sided games were scheduled over a six-week period during the semester.

\section{Participants}

Sixteen undergraduate basketball players were recruited from the Northwest University of Sport Men's and Women's basketball program (eight male; age $19.2 \pm 0.3 \mathrm{y}$, height $1.86 \pm 0.06 \mathrm{~m}$, mass $82 \pm 4 \mathrm{~kg}$; mean $\pm \mathrm{SD}$; eight female; age $20.4 \pm 0.7 \mathrm{y}$, height $1.73 \pm 0.09 \mathrm{~m}$, mass $70 \pm 6 \mathrm{~kg}$ ). All participants and teachers gave informed consent and ethics approval was obtained from the Northwest University of Department of Sports. Due to injury or illness six of the undergraduate basketball players were not able to compete in all versions of basketball games. In these cases, other squad members of the same position were used as replacements. Comparisons were only made between game variations that were played by the same undergraduate basketball player.

\section{Procedures}

Each of the eight variations of a college basketball training was conducted at the beginning of a regular training session, following a standardized five minute warmup. The male and female participants were divided into two groups of four which competed against each other in a tournament style format. Each group undertook one of the games during each session. The same pair or quad grouping of players was used throughout the study of 19 games. The teams were controlled for positional balance by including one or two perimeter and post players each in $2 \mathrm{v} 2$ or $4 \mathrm{v} 4$ games, respectively. Due to a shortage in player numbers, five $2 \mathrm{v} 2$ games were only played once. Scores were recorded and an incentive offered to the group with the most wins at the end of the study period. Verbal encouragement was given by the physical education teacher during the games. No technical or tactical aspects of basketball were emphasized to avoid influencing the players' style of play. Slight rule modifications including a 12 second shot-clock and rewarding a point when being fouled in shooting motion to exclude foul shots, were incorporated to allow for continuous play.

The physiological, physical and technical demands of each game were quantified through heart rate monitoring, sessional rating of perceived exertion (RPE) taken one min after the end of the game, movement pattern analysis and video coding. Heart rate profiles were captured through a commercially available telemetry heart rate system. Values were expressed as mean and peak heart rate as a percentage of each subject's individual maximum heart rate (HRmax), percentage of time spent in Zone 4 (80-89\% of HRmax), and Zone 5 (90-100\% of HRmax). While technical demands were coded as dribbling, passing, midrange shots (shots outside key area, within 3 point line), 3 point shots (shots outside 3 point line), close range shots (shots within key area), rebounding and ball-screens. The technical demand of each small sided game was indicated by the frequency of each of the technical elements. Estimating the frequency of movement patterns has good reliability with a coefficient of variation of $2-4 \%$. Test-retest reliability of the frequency of technical elements was deemed acceptable with an in trackless correlation of 0.99 and typical error of $4 \%$.

\section{Statistical analysis}

Technical, physical and physiological data of each player was collated into an MS Excel database. Gender as a covariate had no clear effect on the dependent variables. The data from the male and 
female participants was thus pooled and analyzed together. All measures were log-transformed prior to analysis to reduce the non-uniformity of error. Comparisons between the college basketball training variables (number of players, court size and work-to-rest ratio) were made by estimating the magnitude of difference of each variable between games. Standardized changes and differences (effect sizes) were calculated with precision of estimation indicated by $90 \%$ confidence limits. An effect was inferred to be unclear if its confidence interval spanned substantial positive and substantial negative values. Clear effects were expressed as substantial and described qualitatively with the following descriptors: trivial 50.2, small 0.2-0.6, moderate $0.6-1.2$, large 1.2-2.0 and very large 42.0. Test-retest reliability for the technical and physical demands was calculated with the typical error of measurement and intraclass correlation coefficient.

\section{Results}

\section{Technical demands}

The number of players per team had the largest effect on all technical elements. The total number of technical elements per undergraduate player was substantially higher $(* 60 \%)$ in $2 \mathrm{v} 2$ games (Figure 1) compared to $4 \mathrm{v} 4$ games. The number of close range shots performed was three fold higher in $2 \mathrm{v} 2$ college basketball training. The number of dribbles, passes, rebounds and ball screens were moderately higher in 2v2 games. Similarly, the number of mid-range jump shots and 3-point shots were higher in 2v2 games (Table 1). The quadrants outlined in Figure 1 show that 2v2 games elicited five technical elements per min. Court size was less influential on the technical demands. Half court games elicited $* 20 \%$ more total technical elements and passing than full court games. Except for ball-screens, the number of all other technical elements was substantially higher in half court games. The work-to-rest ratio had a small effect on the overall technical demands with $4+2$ (difference in means $+90 \%$ confidence limits) more technical elements in $4 \times 2.5$ min type games. There were no substantial differences in the number of individual technical elements between $4 \times 2.5$ min or $2 \times 5$ min small-sided games. The coefficient of variation for the total number of technical elements from game to game across all combinations of the college basketball training was $34 \%$.

\section{Physiological and physical demands}

The number of players had the largest influence on PE scores (Figure 2). RPE scores (scaled 1-10) were moderately higher by two units in $2 \mathrm{v} 2$ games compared to $4 \mathrm{v} 4$ games. Mean heart rate was also substantially higher in $2 \mathrm{v} 2$ games by $* 3+1$ beats per min (difference in mean $+90 \%$ confidence limits). Court size had a moderate effect on RPE with full court games eliciting higher RPE ratings than halfcourt games. No clear substantial differences were seen in any of the heart rate variables for court size (Table 2). Mean heart rate was moderately higher in 2x5-min college basketball training compared to $4 \times 2.5$-min types. RPE was substantially higher and the amount of time spent at $490 \%$ of maximum heart rate was two-fold longer in $2 \times 5$-min college basketball training. Conversely, time spent with a heart rate in the range of $80-89 \%$ of maximum heart rate was substantially longer in the college basketball training with $4 \times 2.5$-min work-to-rest ratios.

\section{Discussion}

The results from this study allow a better understanding of the effect of different variables on the technical, physiological and physical demands of small-sided games using a 12 second shot-clock. This is the first study to systematically investigate the effect of the number of players, court size and work to-rest ratios on the various demands of small-sided basketball games. The main finding is that the number of players has the largest influence on the technical, physiological and high intensity movement patterns in small-sided basketball games.

\section{Technical demands}

The number of players had the largest influence on the technical demands with $2 \mathrm{v} 2$ games involving $60 \%$ more technical executions than $4 \mathrm{v} 4$ games. This finding was not surprising as the smaller number of players in a team allows for more 'ball touches' and hence skill executions per 
player. A similar finding of more touches with fewer players has been reported in small-sided football games. Especially close range shots were performed more frequently in $2 \mathrm{v} 2$ games. This finding supports the use of $2 \mathrm{v} 2$ games for incorporating a higher number of repetitions of close range shots which are a key performance indicator in differentiating winning from losing teams[6].

While decreasing the number of players and thus increasing the amount of ball touches would be beneficial for individual skill development, the addition of players shows an increase in the total number of technical actions performed overall. The value of involving a larger number of players in college basketball training therefore lies in enhancing team-specific decision making skills-more team members and opposition players are involved in the decision making processes. Additionally, technical demands executed without the ball such as cutting, off-ball screening, maintaining spacing, sealing, and leading were not coded. Assessing the frequency of these technical elements may distinguish the technical demands of $2 \mathrm{v} 2$ and $4 \mathrm{v} 4$ small-sided games. It is likely that technical elements executed without the ball occur more frequently in 4v4 games than 2v2 games[7].

\section{Physiological and physical demands}

When designing college basketball training from a conditioning point of view, choosing the number of players per team seems to have the largest influence on the physiological demands and high intensity movement patterns. Using fewer players in a team increases the relative court area per player forcing players to be more involved in game play. These adjustments increase the physiological demands and high intensity movement patterns.

Understanding the influence of the different college basketball training on the physiological and physical demands allows physical education teacher to design specific basketball conditioning games according to specific conditioning goals. Full court, 2v2 2x5 min college basketball training have the highest cardiovascular demand and induce physiological responses required for aerobic adaptations. Half-court, $4 \times 2.5$ min college basketball training provoke more moderate to high intensity shuffling type movement patterns and changes in movement that replicate a majority of specific competition demands. Teacher should explore possibilities with the 12 second shot-clock in college games to ensure physical and physiological loads are high enough to promote improvements in conditioning [8].

The findings from this research can help teacher to plan and program their training sessions to meet specific technical and conditioning goals. It is now clear that $2 \mathrm{v} 2$ small-sided games involve the highest technical and physiological demands. Manipulating court size and work-to-rest ratio influences the balance between technical and physiological/physical demands. An improved understanding of how to modify the demands of college basketball training will assist teacher to prescribe more effective training loads and periodical training programs. Further research in game-based conditioning basketball drills is needed to clarify the effects of different variations (e.g. $1 \mathrm{v} 1$ and $3 \mathrm{v} 3$ ) of small-sided games that influence technical, physiological and physical demands.

\section{Summary}

The number of players on court has the largest effect on physiological and technical demands in college basketball training. Court size and work-to-rest ratios can also influence the frequency of various movement patterns. Physical education teacher can manipulate different variables of college games to establish the technical, physiological and physical demands of their basketball practice. When planning game-based drills with a small number of players, the frequency of technical elements and thus skill repetition in these games will be high. The effect on the physical and physiological load of $2 \mathrm{v} 2$ must also be considered. The physical and physiological demands of $2 \mathrm{v} 2$ college basketball training are substantially higher than $4 \mathrm{v} 4$ games. Full court, $2 \times 5$ min games will create more low to moderate intensity movements and higher cardiovascular demands. 


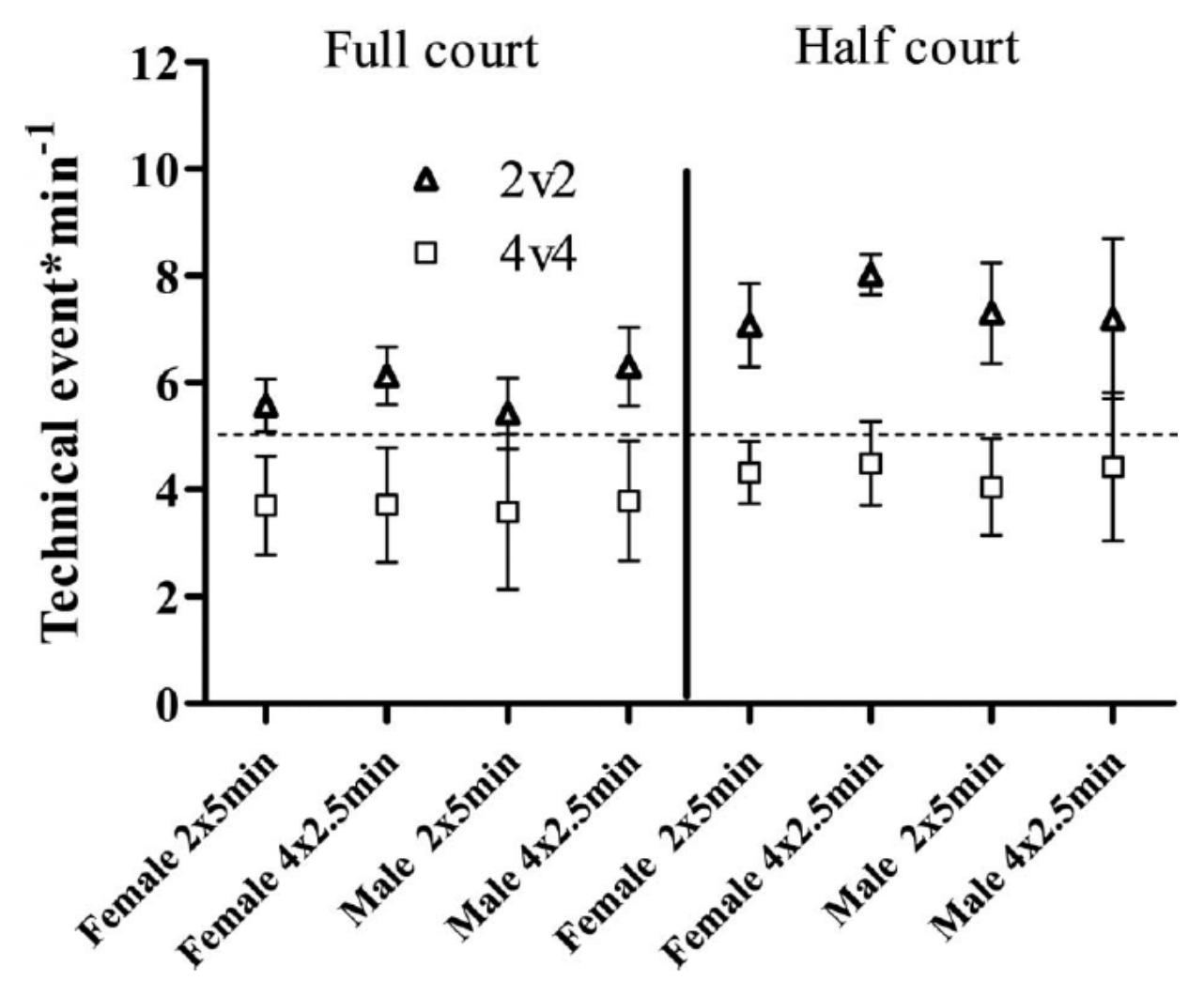

Fig.1. Comparison of technical elements per min for $2 \mathrm{v} 2$ and $4 \mathrm{v} 4$, full court and half court games. Subject gender and $265 \mathrm{~min}$ and $462.5 \mathrm{~min}$ work-to-rest ratios indicated on $\mathrm{x}$-axis. Bars indicate mean $\pm \mathrm{SD}$.

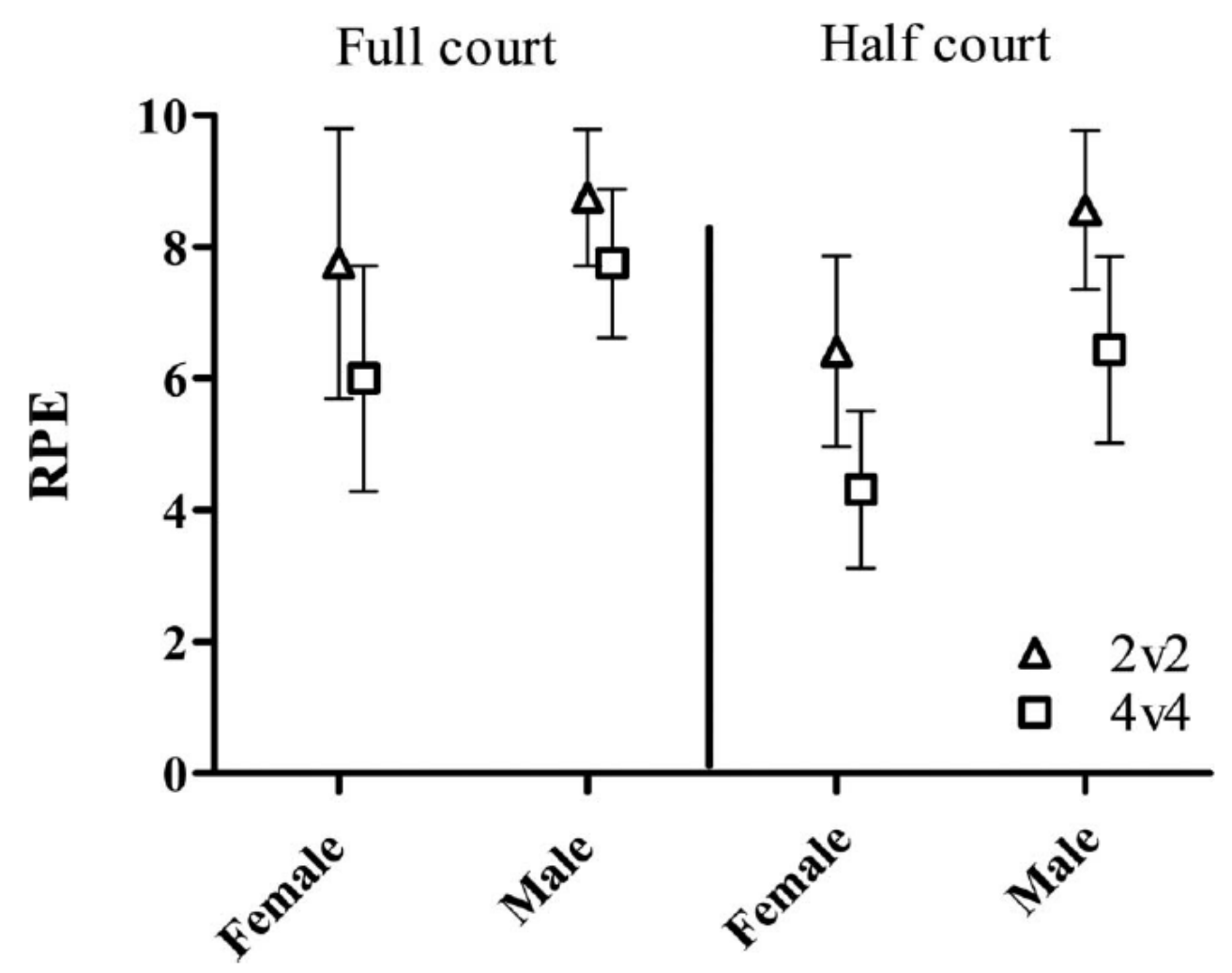

Fig.2. Comparison of rate of perceived exertion (RPE) responses to $2 \mathrm{v} 2$ and $4 \mathrm{v} 4$, full court and half court games. RPE values were substantially higher for full court and 2v2 college baketball games. Bars indicate mean \pm SD. 
Table I. Magnitude of difference (effect size $+90 \%$ confidence limits) in number of technical elements between different variables of smallsided games. *substantial difference.

\begin{tabular}{|c|c|c|c|c|c|c|}
\hline \multirow{2}{*}{$\begin{array}{c}\text { Technical Element } \\
\text { per player per } \\
\text { game) }\end{array}$} & \multicolumn{2}{|c|}{ Player number $(4 \mathrm{v} 4 ; 2 \mathrm{v} 2)$} & \multicolumn{2}{|c|}{ Court size (Half; Full) } & \multicolumn{2}{c|}{$\begin{array}{c}\text { Work-to-rest ratio } \\
(2 \times 5 \mathrm{~min} ; 4 \times 2.5 \text { min })\end{array}$} \\
\cline { 2 - 7 } & mean $\pm \mathrm{SD}$ & $\begin{array}{c}\text { Effect size } \\
\pm \mathrm{CL}\end{array}$ & mean $\pm \mathrm{SD}$ & $\begin{array}{c}\text { Effect size } \\
\pm \mathrm{CL}\end{array}$ & $\begin{array}{c}\text { mean } \\
\pm \mathrm{SD}\end{array}$ & $\begin{array}{c}\text { Effect size } \\
\pm \mathrm{CL}\end{array}$ \\
\hline Total Elements & $43 \pm 10 ; 68 \pm 12$ & $2.28 \pm 0.30^{*}$ & $57 \pm 18 ; 46 \pm 13$ & $0.64 \pm 0.17^{*}$ & $51 \pm 17 ; 55 \pm 18$ & $0.22 \pm 0.13^{*}$ \\
\hline & & very large & & moderate & & small \\
\hline Dribble & $12 \pm 5 ; 20 \pm 6$ & $1.18 \pm 0.27^{*}$ & $16 \pm 8 ; 13 \pm 6$ & $0.32 \pm 0.18^{*}$ & $14 \pm 7 ; 15 \pm 8$ & $0.18 \pm 0.15$ \\
\hline & & moderate & & small & & trivial \\
\hline Pass & $15 \pm 5 ; 19 \pm 5$ & $0.94 \pm 0.31^{*}$ & $18 \pm 6 ; 14 \pm 4$ & $0.75 \pm 0.23^{*}$ & $16 \pm 5 ; 17 \pm 6$ & $0.17 \pm 0.16$ \\
\hline & & moderate & & moderate & & $0.07 \pm 0.24$ \\
\hline Close range shot & $3 \pm 2 ; 8 \pm 3$ & $1.71 \pm 0.37^{*}$ & $6 \pm 4 ; 5 \pm 3$ & $0.32 \pm 0.26^{*}$ & $6 \pm 3 ; 6 \pm 4$ & trivial \\
\hline Mid-range jump & $2 \pm 2 ; 4 \pm 3$ & $0.44 \pm 0.33^{*}$ & $3 \pm 3 ; 2 \pm 2$ & $0.53 \pm 0.38^{*}$ & $3 \pm 2 ; 3 \pm 3$ & $0.17 \pm 0.27$ \\
\hline shot & & small & & small & & trivial \\
\hline 3 -point shot & $2 \pm 2 ; 3 \pm 3$ & $0.37 \pm 0.36^{*}$ & $3 \pm 3 ; 2 \pm 2$ & $0.30 \pm 0.29^{*}$ & $2 \pm 2 ; 2 \pm 3$ & $0.11 \pm 0.23$ \\
\hline & & small & & small & & trivial \\
\hline Rebound & $5 \pm 3 ; 8 \pm 3$ & $1.18 \pm 0.38^{*}$ & $7 \pm 2 ; 5 \pm 3$ & $0.58 \pm 0.25^{*}$ & $6 \pm 3 ; 7 \pm 3$ & $0.23 \pm 0.27$ \\
\hline & & moderate & & small & & trivial \\
\hline Ball Screen & $3 \pm 3 ; 5 \pm 4$ & $1.17 \pm 0.44^{*}$ & $4 \pm 4 ; 4 \pm 5$ & $0.24 \pm 0.34$ & $3 \pm 4 ; 4 \pm 4$ & $0.15 \pm 0.30$ \\
\hline & & moderate & & unclear & & unclear \\
\hline
\end{tabular}

Table II. Magnitude of difference in RPE and heart rate data (effect size $+90 \%$ confidence limits; qualitative descriptor) between different variables of small-sided games. *substantial difference.

\begin{tabular}{|c|c|c|c|c|c|c|}
\hline \multirow{2}{*}{$\begin{array}{l}\text { Physiological } \\
\text { demand }\end{array}$} & \multicolumn{2}{|c|}{ Player number $(4 \mathrm{v} 4 ; 2 \mathrm{v} 2)$} & \multicolumn{2}{|c|}{ Court size (Half; Full) } & \multicolumn{2}{|c|}{$\begin{array}{l}\text { Work-to-rest ratio } \\
\text { (2x5 min; 4x2.5 min) }\end{array}$} \\
\hline & mean $\pm \mathrm{SD}$ & $\begin{array}{l}\text { Effect size } \\
\pm \mathrm{CL}\end{array}$ & mean $\pm \mathrm{SD}$ & $\begin{array}{l}\text { Effect size } \\
\pm \mathrm{CL}\end{array}$ & $\begin{array}{l}\text { mean } \\
\pm \mathrm{SD}\end{array}$ & $\begin{array}{l}\text { Effect size } \\
\quad \pm \mathrm{CL}\end{array}$ \\
\hline \multirow[t]{2}{*}{ RPE } & $6 \pm 2 ; 8 \pm 2$ & $0.95 \pm 0.26^{*}$ & $6 \pm 2 ; 7 \pm 2$ & $0.62 \pm 0.22 *$ & $7 \pm 2 ; 7 \pm 2$ & $-0.50 \pm 0.23 *$ \\
\hline & & moderate & & moderate & & small \\
\hline \multirow[t]{2}{*}{$\begin{array}{c}\text { Peak heart rate } \\
\text { as } \% \text { of max heart } \\
\text { rate }\end{array}$} & $92 \pm 3 ; 92 \pm 3$ & $0.28 \pm 0.29 *$ & $92 \pm 3 ; 92 \pm 3$ & $0.06 \pm 0.26$ & $92 \pm 3 ; 92 \pm 2$ & $0.17 \pm 0.22$ \\
\hline & & small & & trivial & & trivial \\
\hline \multirow[t]{2}{*}{$\begin{array}{c}\text { Mean heart rate } \\
\text { as } \% \text { of } \\
\text { max heart rate } \\
\end{array}$} & $83 \pm 5 ; 86 \pm 4$ & $0.53 \pm 0.26^{*}$ & $84 \pm 5 ; 85 \pm 4$ & $0.18 \pm 0.21$ & $86 \pm 4 ; 83 \pm 3$ & $0.83 \pm 0.19 *$ \\
\hline & & moderate & & trivial & & moderate \\
\hline \multirow[t]{2}{*}{$\begin{array}{c}\text { Mean \% time } \\
\text { spent in } \\
\text { Zone4 (80-89\% } \\
\text { HR max) }\end{array}$} & $51 \pm 20 ; 55 \pm 24$ & $0.10 \pm 0.40$ & $46 \pm 27 ; 56 \pm 19$ & $0.18 \pm 0.33$ & $53 \pm 26 ; 58 \pm 9$ & $0.43 \pm 0.29 *$ \\
\hline & & unclear & & unclear & & small \\
\hline \multirow[t]{2}{*}{\begin{tabular}{|c|} 
Mean $\%$ time \\
spent in \\
Zone5 $(80-89 \%$ \\
HR max $)$ \\
\end{tabular}} & $22 \pm 25 ; 30 \pm 31$ & $0.10 \pm 0.33$ & $20 \pm 27 ; 25 \pm 27$ & $0.18 \pm 0.40$ & $33 \pm 32 ; 14 \pm 13$ & $0.49 \pm 0.32 *$ \\
\hline & & unclear & & unclear & & small \\
\hline
\end{tabular}

\section{References}

[1] G. Jones, S. Hanton, D. Connaughton. What is this thing called mental toughness? An investigation of elite sports performers. J Appl Sport Psychol, 14 (2002) 205-218. 
[2] Impellizzeri et al, F.M. Impellizzeri, E. Rampinini, N. Maffiuletti, S.M. Marcora A vertical jump force test for assessing bilateral strength asymmetry in athletes. Medicine and Science in Sports and Exercise, 39 (2007) 2044-2050.

[3] Castagna, C., Impellizzeri, F.M., Chaouachi, A., Ben Abdelkrim, N., \& Manzi, V. (2011). Physiological responses to ball-drills in regional level male basketball players. Journal of Sports Sciences, 29(2011) 1329-1336.

[4] D. Laplaud, F. Hug, R. Menier. Training-İnduced Changes in Aerobic Aptitudes of Professional Basketball Players International Journal of Sports Medicine, 25(2004) 103-108.

[5] Csataljay, G., O’Donoghue, P., Hughes, M., \& Dancs, H. Performance indicators that distinguish winning and losing teams in basketball. International Journal of Performance Analysis of Sport, $9(2011) 60-66$.

[6] Gabbett, T.J., Jenkins, D., \& Abernethy, B. Physiological and skill demands of on-side and off-side games. Journal of Strength \& Conditioning Research, 24(2010) 2979-2983.

[7] O. Pamuk, T. Kaplan, H. Taskin, N. Erkmen. Examination of the Some Physical and Physiological Parameters on Basketball Players According To Different Leagues Sportster. Journal of Physical Education and Sport Science, VI (3) (2008) 141-144.

[8] O. Fliess-Douer, Y. Hutzler, Y. Vanlandewijck. The relationship between the level of physical impairment and goal perspectives in wheelchair basketball players Perceptual and Motor Skills, 96 (2003) 755-758. 